\title{
Kudzu Extract Treatment Does Not Increase the Intoxicating Effects of Acute Alcohol in Human Volunteers
}

\author{
David M. Penetar, Ph.D. ${ }^{*}$, Robert R. MacLean, B.S., Jane F. McNeil, B.A., M.H.P., and Scott \\ E. Lukas, Ph.D. \\ Behavioral Psychopharmacology Research Laboratory, McLean Hospital/Harvard Medical School
}

\begin{abstract}
Background-Isoflavone administration in the form of a purified extract from the herbal medication kudzu root has been shown to reduce, but not eliminate, alcohol consumption in alcohol-abusing and alcohol-dependent men. The precise mechanism of this action is unknown, but one possible explanation for these results is that the isoflavones in kudzu might actually increase the intensity or duration of alcohol's effects and thus delay the desire for subsequent drinks. The present study was designed to test this hypothesis.
\end{abstract}

Methods-Twelve (12) healthy adult men and women (27.5 \pm 1.89 yrs old) who consumed moderate amounts of alcohol ( $7.8 \pm 0.63$ drinks/week) participated in a double-blind, placebocontrolled crossover study in which they were treated with either kudzu extract (total isoflavone dose of $750 \mathrm{mg}$ /day) or matched placebo for nine days. On days 8 and 9, participants received an acute challenge of ethyl alcohol (either 0.35 or $0.7 \mathrm{~g} / \mathrm{kg}$ alcohol). During the challenges the following measures were collected: subjective effects, psychomotor (body sway), cognitive performance (vigilance/reaction time), physiological measures (heart rate and skin temperature), and plasma ethanol concentration.

Results-Alcohol resulted in a dose-related alteration in subjective measures of intoxication, impairment of stance stability, and vigilance/reaction time. Kudzu extract did not alter participants' subjective responses to the alcohol challenge or to alcohol's effects on stance stability or vigilance/reaction time. However, individuals treated with kudzu extract experienced a slightly more rapid rise in plasma ethanol levels, but only after the $0.7 \mathrm{~g} / \mathrm{kg}$ dose. This transient effect during the first 30 minutes of the ascending plasma alcohol curve lasted only 10-15 minutes; there were no differences in peak plasma alcohol levels or alcohol elimination kinetics.

Additionally, kudzu pretreatment enhanced the effects of the $0.7 \mathrm{~g} / \mathrm{kg}$ dose of alcohol on heart rate and skin temperature.

Conclusions-These data suggest that individuals who drink alcohol while being treated with kudzu extract experience no adverse consequences and further, the reported reductions in alcohol intake after kudzu extract treatment are not related to an alteration in alcohol's subjective or psychomotor effects.

\section{Keywords}

kudzu; isoflavone; puerarin; alcohol; psychomotor

*Corresponding Author: David M. Penetar, Ph.D., McLean Hospital/Harvard Medical School, 115 Mill Street, Belmont, MA 02478, Phone: 617-855-2913, Fax: 617-855-3711, dpenetar@mclean.harvard.edu. 


\section{Introduction}

Historical texts have documented the use of kudzu and kudzu-containing plants to treat alcohol-related problems. One such Chinese herbal medicine XJL (NPI-028), which contains the extracts of several plants including Puerariae lobata (kudzu) and Citrus reticulata, has long been used to reduce the inebriation that results from alcohol consumption (Li, 1590-1596; Sun, circa $600 \mathrm{AD}$ ). The utility of kudzu extract as a supplemental treatment to alcohol dependence within Western society has received little attention. Recently, however, reports from preclinical and clinical studies discussed below suggest that extracts of the kudzu root significantly reduce alcohol consumption.

Kudzu is comprised of three major isoflavones: daidzin, daidzein, and puerarin. In preclinical studies with Syrian Golden hamsters, Keung and Valee (1993) demonstrated that preparations of daidzin and daidzein suppressed alcohol intake in a free choice drinking (water vs. ethanol) paradigm by more than 50\%. Alcohol (but not water) intake was suppressed while the animals received the isoflavone treatment with consumption returning to pre-treatment levels in approximately 5 days. Overstreet et al. (1996) showed that the herbal medicine NPI-028 effectively reduced ethanol intake in alcohol-preferring rats. Similarly, Heyman et al. (1996) showed that daidzin dose-dependently reduced ethanolreinforced lever pressing and ethanol consumption in rats. Lin et al. (1996) found that all three isoflavonoids isolated from kudzu (daidzin, daidzein, and puerarin) decreased alcohol consumption by female alcohol-preferring rats by $75 \%, 50 \%$, and $42 \%$, respectively. Overstreet showed that NPI-028 suppressed alcohol intake in alcohol-preferring rats and monkey without inducing taste aversion (Overstreet et al., 1998). In the first demonstration of kudzu's effectiveness in humans, Lukas et al. (2005) showed a significant decrease in beer consumption during a 1.5 hour drinking session after pretreatment with extract comprised of all three isoflavones.

Although several theories have emerged, the specific mechanism(s) of action of these isoflavonoid compounds is not known. Keung (2002) lists several known effects of daidzin and speculates how these may act to reduce alcohol consumption. Daidzin is known to be a selective inhibitor of aldehyde dehydrogenase, the major enzyme responsible for the breakdown of acetaldehyde which is the primary metabolite of alcohol oxidation. By preventing acetaldehyde breakdown and allowing it to build to high levels in the body, alcohol consumption would cause an aversive reaction similar to disulfiram (Antabuse ${ }^{\mathrm{TM}}$ ), eliminating positive effects of alcohol and limiting consumption. This mechanism is unlikely however, at least in non-humans, as additional findings indicated that daidzin administration at doses that reduce alcohol intake in hamsters did not change acetaldehyde metabolism (Keung et al., 1995). Another effect may involve alterations in the mitochondrial monoamine oxidase-acetaldehyde pathway. Daidzin affects the breakdown of serotonin and dopamine into the primary metabolites 5-hydroxyindole acetic acid (5-HIAA) and 3,4-dihydroxyphenyl acetic acid (DOPAC) respectively. The net result would allow the metabolic intermediates (5-hydroxyindole acetaldehyde [5-HIAL] and 3,4-dihydroxyphenyl acetaldehyde [DOPAL]) to accumulate. As a consequence, daidzin could reduce alcohol consumption by altering monoamines that are important in central reward pathways (Rooke et al., 2000). Supporting evidence by Keung et al. (1995) has shown that the ability of structural analogs of daidzin to increase 5-HIAL accumulation is positively correlated with the compound's alcohol-suppressing capabilities. The significance and application of this finding to other isoflavone compounds (e.g., puerarin) and to the human mitochondrial pathway system remains unknown.

Previously in our laboratory, we demonstrated that 7 days pretreatment with kudzu extract containing $19 \%$ puerarin, $4 \%$ daidzin, $2 \%$ daidzein (total isoflavone dose of $750 \mathrm{mg} /$ day) 
significantly reduced alcohol consumption by binge drinkers in a naturalistic setting (Lukas et al., 2005). An analysis of the participant's alcohol craving or urge to drink prior to the drinking session revealed that neither was affected by kudzu pretreatment. During the session, only drinking amounts and patterns were recorded to avoid interfering with the participant's alcohol self administration behavior so it is not known if the subjective effects of alcohol were affected. The present study was conducted to assess the effects of kudzu extract after alcohol consumption on several behavioral, psychomotor, cognitive, and physiological measures in an attempt to uncover potential drug interactions.

\section{Materials and Methods}

\section{Participants}

Twelve (12) physically and mentally healthy adult volunteers (6 male) with a mean age $27.6 \pm 1.89$ yrs old signed informed consent to participate in this multi-visit study. Participants weighed on the average $165.5 \pm 11.1$ pounds and had an average body mass index of $25.3 \pm 1.3$. They consumed $7.8 \pm 0.63$ drinks per week and did not abuse nor were dependent on any drug. Two smoked tobacco cigarettes. The protocol and informed consent were approved by the McLean Hospital Institutional Review Board and individuals were paid for their participation.

\section{Materials}

Kudzu extract-An extract of the kudzu root (NPI-031, Alkontrol-Herbal ${ }^{\circledR}$, Natural Pharmacia International, Inc., Burlington, MA) was administered in $500 \mathrm{mg}$ capsules containing sugar beet-based filler and three primary isoflavones: puerarin (19\%), daidzin (4\%), and daidzein (2\%); this preparation was used in previous studies from this laboratory (Lukas et al., 2005; Penetar et al., 2006). In order to replicate the pretreatment condition from Lukas et al. (2005), the same pretreatment time period prior to the first drinking session ( 7 days) was utilized in the present study. Participants took 2 capsules three times a day for a $750 \mathrm{mg}$ total dose of isoflavones. Identically appearing placebo capsules contained just the sugar beet filler. In addition, participants consumed a third capsule (in the morning and evening doses only) that contained $25 \mathrm{mg}$ of riboflavin (vitamin B2). Riboflavin causes the urine to fluoresce when viewed under ultraviolet light and was used as a measure of medication compliance (Del Boca, 1996).

Acute Alcohol Challenge-Alcoholic drinks were made by mixing a name brand vodka (80 proof) with chilled orange juice. Volumes were individually adjusted to deliver a dose of either 0.35 or $0.70 \mathrm{~g} / \mathrm{kg}$ in $400 \mathrm{ml}$ of total volume. The mixture was poured into 3 equal volume cups and placed on ice until administration. At the appropriate time, participants were instructed to consume one cup at a time over a 15-minute period; participants had 5 minutes to consume the contents of each cup. Placebo drinks consisted of $400 \mathrm{ml}$ of orange juice only, divided into 3 cups. A few drops of vodka were placed in each cup on top of the orange juice just prior to administration to provide a mild alcohol aroma.

Subjective Behavioral Measures-Participants rated their response to the alcohol challenge on the following visual analog scales: feel alcohol effects, clumsy, dizzy, drunk, floating, great, high, muddled/confused, nauseated, sleepy, slurred speech, terrible, and uncomfortable. Scales were on a 100-point visual analog scale (VAS) from 0 - 'not at all' to 100 - 'extremely'. Questionnaires were administered on a computer screen in front of the participant 30, 45, and 60 minutes after the start of alcohol administration; after 1 hour, questionnaires were administered every 30 minutes until the end of the session at 3 hours. 
Stance Stability/Body Sway-A new custom-built platform, based on an earlier design (Lukas et al., 1989) was used to measure stance stability/body sway. The device consisted of a $0.76 \mathrm{~m}$ square plywood platform mounted on 4 pressure sensitive load cells. Output from the cells was collected on a dedicated computer running software that computed a single point in Cartesian coordinate system at a rate of $20 \mathrm{~Hz}$. Stability/sway was defined as an area measurement of the total points collected in a 30-second period. As this was one of the initial uses of the device, 4 different stance positions were evaluated. The subjects stood erect on the platform with feet together with their eyes either open or closed, and with their arms either by their side or extended to the side with their palms facing upward. Participants were told to relax between each 30-second collection period, but did not move their feet. Assessments were performed after completion of the questionnaires at 30, 45, and 60 minutes after start of alcohol administration; after 1 hour, stance stability was assessed every 30 minutes until the end of the session at 3 hours.

Cognitive Assessment-A computerized Continuous Performance Test II (CPT II) (Conners, 2000) was used to assess sustained attention and concentration abilities. The test requires individuals to press the space bar as quickly as possible following the appearance of a letter on a laptop computer screen, but to withhold pressing for any occurrence of the letter ' $X$ '. Interstimulus intervals (ISI) vary between 1,2, and 4 seconds with a display time of 250 milliseconds. The test structure consists of 6 blocks and 3 sub-blocks, each containing 20 trials (letter presentations). The presentation order of the different ISIs varies between blocks and takes about 15 minutes to complete. The CPT II was administered on a separate laptop computer in the experimental chamber at 45 and 60 minutes after alcohol administration; after 1 hour, CPT II was administered every 30 minutes until the end of the session at 3 hours.

Physiological Measures-Heart rate (beats per minute or bpm) and skin temperature $\left({ }^{\circ} \mathrm{C}\right)$ recordings were made continuously with a Mini Logger Series 2000 device (Mini Mitter, Bend, OR). Heart rate was recorded via a Polar chest belt monitor. Skin temperature was recorded using single-use thermister-based temperature probes (Steri-Probe, Cincinnati Sub-Zero Products, Cincinnati, $\mathrm{OH}$ ) attached to the back of the middle finger on the nondominant hand and connected to a port in the logger.

Blood sampling procedures/plasma analysis-An intravenous catheter (KowarskiDakmed Thromboresistant Blood Withdrawal Needle and 8 foot Tubing Set; Dakmed, Inc., Buffalo, NY) was inserted in an antecubital vein for withdrawal of blood samples 20 minutes before the alcohol administration. The distal end of the catheter was passed through an opening in the chamber wall and attached to a $10-\mathrm{ml}$ syringe mounted on a withdrawal syringe pump (Lukas et al. 1986). Syringes were changed every 5 minutes and the blood was put into Vacutainer ${ }^{\circledR}$ tubes containing $\mathrm{K}_{3}$ EDTA $(12 \mathrm{mg})$ as anticoagulant and placed on ice. The blood samples were then centrifuged and the plasma separated into a plastic vial. Quantitative analysis of ethanol levels was performed by gas chromatography with flame ionization detection (GC/FID) (Hewlett-Packard model 5890 series II equipped with a model 18593B autosampler) (Penetar et al., 2008). Analysis was performed on every 5 minute sample after the commencement of drinking for 75 minutes, and on samples taken at $90,120,150$, and 180 minutes.

\section{Procedure}

In this double blind, placebo-controlled study participants were randomly assigned to receive either the low $(0.35 \mathrm{~g} / \mathrm{kg})$ or high $(0.7 \mathrm{~g} / \mathrm{kg})$ dose of alcohol (6 per group). Participants were treated for a total of 9 days with either kudzu extract or placebo. On days 8 and 9, laboratory drinking sessions were conducted where measurements of subjective 
effects of intoxication, stance stability/body sway assessments, cognitive ability, physiological monitoring of heart rate and skin temperature, and repeated blood samples for plasma ethanol concentrations were performed over a span of three hours. Day 8 always consisted of a placebo (orange juice only) drink challenge, while day 9 consisted of an alcohol drink challenge of either the high or low dose depending on group randomization. Participants were told only that the drinking sessions could be with placebo, or a low or high dose of alcohol. The drinks were administered between 2 and 2.5 hours after consumption of the morning dose of medication as blood levels of puerarin peak at this time (Penetar et al., 2006). Participants continued to take their medication through the morning of day 9 prior to the alcohol drink challenge. Following the first set of challenge sessions, there was a 1 month 'washout' period during which no medication was taken. This washout period provided ample time to eliminate pharmacodynamic interactions between kudzu and placebo treatment conditions. After the one-month washout, a second period of treatment and two drinking challenge days was conducted identical to the first treatment period. Treatment was counterbalanced across participants.

\section{Pharmacokinetic and Statistical Analyses}

Pharmacokinetic results were obtained using PK Solutions 2.0 (Summit Research Services, Montrose, CO; www.SummitPK.com). A linear mixed model analysis of variance (SPSS 13.0 for MAC OS X) was performed for dependent variables using the main factors of dose, pretreatment condition, and time, as appropriate. Post hoc testing was performed with Bonferroni correction.

\section{Results}

\section{Subjective Behavioral Measures}

Significant alcohol dose effects were observed for ratings on all of the visual analog scales (Table 1). The $0.35 \mathrm{~g} / \mathrm{kg}$ dose produced significant increases in ratings compared to placebo on all scales except clumsy, floating, muddled/confused, slurred speech, and uncomfortable. The $0.7 \mathrm{~g} / \mathrm{kg}$ dose produced significant differences from the $0.35 \mathrm{~g} / \mathrm{kg}$ dose on all scales except clumsy and nauseated. The dose and time course effects on selected scales of positive alcohol effects and negative alcohol effects are shown in Figure 1. Instances of kudzu pretreatment effects were observed on one scale of negative alcohol effects (dizzy). Ratings of dizzy following the kudzu pretreatment period were significantly elevated over the placebo pretreatment period for 60 minutes following the $0.7 \mathrm{~g} / \mathrm{kg}$ alcohol dose (Figure 1, bottom).

\section{Stance Stability/Body Sway}

Overall, body sway was more pronounced when the participant's eyes were closed vs. eyes open $([\mathrm{F}(3,168)=12.805, \mathrm{p}<.001]$ and a clear dose effect was observed $[\mathrm{F}(2,168)=8.129, \mathrm{p}<$. 001] with intermediate effects observed with the $0.35 \mathrm{~g} / \mathrm{kg}$ dose and the largest effects observed with the $0.7 \mathrm{~g} / \mathrm{kg}$ dose. For the $0.7 \mathrm{~g} / \mathrm{kg}$ dose, sway was significantly worse than baseline up to $120 \mathrm{~min}$ after ingestion. The dose and time course values for the two stances with eyes closed are shown in Figure 2. These effects were not different due to pretreatment condition.

\section{Cognitive Assessment}

Alcohol affected several measures of the CPT II test. The number of omissions ('misses', i.e. not pressing the space bar for all non-X letters) significantly increased in comparison to placebo and the $0.35 \mathrm{~g} / \mathrm{kg}$ dose, and these effects were greatest at 60 and 90 minutes ingesting alcohol [dose: $\mathrm{F}(2,293)=6.150, \mathrm{p}=.002$; time: $\mathrm{F}(6,293)=3.039, \mathrm{p}=.007$ ] (data not 
shown). Reaction time for correct responses was significantly slower after the $0.7 \mathrm{~g} / \mathrm{kg}$ dose $[F(2,293)=21.680, p<.001]$. There were no kudzu extract treatment effects.

\section{Physiological Measures}

Analysis of the 10 minutes following the consumption of the alcoholic beverage revealed that heart rate was significantly elevated by both doses of alcohol. Across both pretreatment conditions and all time points, heart rates averaged $( \pm \mathrm{sem}) 63.9( \pm 0.7) \mathrm{bpm}$ in the placebo condition, and $69.7( \pm 1.2)$ and $72.0( \pm 1.0) \mathrm{bpm}$ following the 0.35 and $0.7 \mathrm{~g} / \mathrm{kg}$ doses of alcohol respectively $[\mathrm{F}(2,308)=23.956, \mathrm{p}<.001]$ (data not shown). Furthermore, there was a pretreatment effect $[F(1,308)=18.116, p<.001]$ and a pretreatment $x$ dose interaction $[\mathrm{F}(2,308)=7.13, \mathrm{p}=.001]$ where subjects had higher heart rates after kudzu pretreatment and this accentuated the response to the $0.7 \mathrm{~g} / \mathrm{kg}$ dose. Heart rates following the $0.7 \mathrm{~g} / \mathrm{kg}$ dose after the kudzu pretreatment averaged $77.3( \pm 1.4)$ bpm vs. $66.7( \pm 1.5)$ bpm after placebo pretreatment. Skin temperature was affected by pretreatment condition: temperatures averaged $( \pm$ sem $) 28.8( \pm 0.3)^{\circ} \mathrm{C}$ after the placebo pretreatment and $29.6( \pm 0.2){ }^{\circ} \mathrm{C}$ after kudzu pretreatment $[\mathrm{F}(1,330)=3.924, \mathrm{p}=.048]$. Furthermore, a significant pretreatment $\mathrm{x}$ dose interaction was found such that skin temperatures following the $0.7 \mathrm{~g} / \mathrm{kg}$ dose were higher following kudzu pretreatment condition $\left(30.7 \pm 0.5^{\circ} \mathrm{C}\right.$ after kudzu vs $27.6 \pm 0.5^{\circ} \mathrm{C}$ after placebo pretreatment) $[\mathrm{F}(2,330)=10.32, \mathrm{p}<.001]$.

\section{Plasma Ethanol Levels}

Plasma ethanol levels rose steadily following consumption to reach a peak between 40 and 60 minutes (Figure 3). Ethanol levels were significantly higher following the $0.7 \mathrm{~g} / \mathrm{kg}$ dose $[\mathrm{F}(1,376)=710.387, \mathrm{p}<.001]$. Furthermore, there was a significant pretreatment $\mathrm{x}$ dose interaction $[\mathrm{F}(1,376)=4.775, \mathrm{p}=.029]$. Post hoc testing revealed that ethanol levels for the $0.7 \mathrm{~g} / \mathrm{kg}$ dose following the kudzu pretreatment period were significantly higher than levels for this dose following the placebo pretreatment period at 20 and 25 minutes after initiation of drinking (Figure 3).

\section{Pharmacokinetic measures}

Values for standard measures of pharmacokinetic parameters are reported in Table 2. Significant dose effects were observed for maximum concentration (Cmax) $[\mathrm{F}(1,19)=95.683, \mathrm{p}<.001]$, absorption rate $[\mathrm{F}(1,19)=11.853, \mathrm{p}=.003]$, Area Under the Curve from time 0 to 180 minutes (AUC0_180) $[\mathrm{F}(1,19)=35.613, \mathrm{p}<.001]$, and Area Under the Curve from time 0 to infinity (AUC0_inf) $[\mathrm{F}(1,19)=94.724, \mathrm{p}<.001]$. Values for the $0.7 \mathrm{~g} / \mathrm{kg}$ dose were significantly higher than values for the $0.35 \mathrm{~g} / \mathrm{kg}$ dose for these measures. Time to maximum concentration (Tmax) and elimination rate were not different between the doses. For all measures, there were no significant differences due to pretreatment condition and no interactions were observed between dose and pretreatment.

\section{Discussion}

The present study demonstrated that pretreatment with kudzu extract had little or no effect on the majority of alcohol's effects on subjective mood, vital signs, psychomotor, or cognitive performance. Although there were specific points of differences between ethanol levels during the absorption phase of the higher alcohol dose due to pretreatment condition, kinetic measures of absorption rate did not reveal an overall pretreatment effect making the significance of this result difficult to interpret at this time. These findings suggest that the ability of kudzu extract to reduce alcohol consumption (Lukas et al., 2005) is not likely to be dependent on a significant alteration of the acute effects of alcohol. 
Acute alcohol administration resulted in expected, dose-related alterations in subjective, psychomotor, cognitive, and physiological effects. These effects typically were greater after the higher dose, and the time course follows the known effects of alcohol (Brasser et al., 2004; Holdstock et al., 2000). Subjective measures of alcohol intoxication were greatest at 30 minutes and returned to or were close to predrinking levels by the end of the assessment period (3 hours). Psychomotor (stance stability/body sway) and cognitive function were most affected at 60 minutes, and they too returned to or were close to baseline by 3 hours. Heart rate and skin temperature effects were collected only for the first 10 minutes after drinking because that was the only period during which the participants were sitting calmly and not required to perform any tasks (and thus offered artifact-free data). During this time, alcohol increased heart rate consistent with previous reports (Kouri et al., 2004; Penetar et al., 2009).

Subjective and psychomotor effects observed after alcohol consumption are typically attributed to be the direct effects of alcohol on the CNS. There are data to suggest that many of these effects may be due, at least in part, to the primary alcohol metabolite, acetaldehyde (Kim et al., 2009). Daidzin has been shown to inhibit hamster and rat mitochondrial aldehyde dehydrogenase (ALDH-2) in vitro and is a mixed inhibitor of the human enzyme (Keung et al., 1997). If isoflavones such as daidzin significantly increase acetaldehyde levels in humans in vivo, then this could be a possible mechanism of action. However, in a pilot toxicity study we found no change in acetaldehyde levels in kudzu-treated humans after drinking alcohol (unpublished data). Furthermore, we did not observe any signs of acetaldehyde-related side effects (e.g., flushing, throbbing in head and neck, throbbing headache, respiratory difficulty, nausea, copious vomiting, sweating, thirst, chest pain, palpitation, dyspnea, hyperventilation, tachycardia, hypotension, syncope, marked uneasiness, weakness, vertigo, blurred vision) in our current or any prior studies. The transient effects of subjective ratings of dizziness alone are insufficient to suggest the presence of a disulfiram-like effect as a result of kudzu administration. Thus, altered acetaldehyde metabolism is not a likely explanation for kudzu extract effects in humans.

As previously mentioned, isoflavone compounds may alter alcohol consumption and effects through alterations in central reward pathways. These pathways may be sensitive not only to alcohol directly, but also to acetaldehyde levels also (Melis et al., 2009; Sanchez-Catalan et al., 2009). The kudzu extract used in the present study was primarily composed of puerarin, but also contained smaller amounts of daidzin and daidzein. Our knowledge of how these compounds affect alcohol consumption and alter behavioral and psychomotor responses is limited at the present time by a lack of human dose-response studies and detailed biochemical studies of alcohol metabolism and central reward pathways after isoflavone administration.

The present study explored possible mechanisms to explain how kudzu extract reduces alcohol consumption in humans. The results imply that a reduction in consumption exhibited in previous studies is not likely due to an increase in the subjective intoxicating effects of alcohol or to an increase in alcohol's effect on psychomotor performance or cognitive processing. However, it is interesting to note that two measures of physiological responses heart rate and skin temperature - were accentuated by kudzu pretreatment. As these effects were seen only after the high alcohol dose, it would appear that this is evidence for a doseresponse type of relationship. In addition, and perhaps of greater significance, is the possibility that ethanol levels rose more quickly at the higher dose of alcohol $(0.7 \mathrm{~g} / \mathrm{kg})$ following kudzu pretreatment compared to placebo pretreatment. One interpretation of this finding is that kudzu extract does not potentiate the intoxicating effects of alcohol, but only hastens the onset of action in a dose-response fashion. In our previous study we demonstrated that the same kudzu extract used in the present study significantly reduced 
beer consumption in binge-drinkers (Lukas et al., 2005). The significance of the effects on the early plasma ethanol levels and the effects on heart rate and skin temperature offer some insight to the potential mechanism of action of kudzu extract in that study. During the present study we have gathered evidence that kudzu extract may alter blood ethanol levels and that this change in pharmacokinetics may result in an increased rate of entry into the central nervous system. Such an effect might increase the rewarding effects of the first drink consumed, especially when higher doses are consumed, and the desire for subsequent drinks might be delayed. Thus, the net effect of kudzu extract would not be to eliminate drinking completely, but to reduce binge drinking to a more manageable number of drinks from which complete withdrawal (via complementary methods) might be possible.

There is empirical evidence for these effects of kudzu extract. First, kudzu extract causes vasodilation in rat artery tissue (Yan et al., 2009; Yeung et al., 2006) and in human vascular tissue (Tam et al., 2009). Second, there is an approved intravenous preparation of puerarin which is used in China to reduce myocardial oxygen consumption and improve cardiac microcirculation (Yue and $\mathrm{Hu}, 1996$; Zhang et al., 2006). Vasodilation would also be expected to result in a mild reflex tachycardia and a corresponding increase in skin temperature due to greater tissue perfusion; both of these effects were observed in the present study.

The concept that a more rapid delivery of alcohol to the brain would result in a decrease (and not an increase) in drinking behavior seems counter intuitive. Yet, in animal studies, a decrease in drug administration has been observed when an animal is self-administering a drug and receives a non-contingent dose from the experimenter, i.e., the next selfadministered dose is delayed (Griffiths et al., 1981; Wurster et al., 1977). Admittedly, the magnitude of the change in plasma ethanol levels in the present study is modest and may not be biologically significant, in spite of the observed statistical significance. We are currently engaged in studies employing proton magnetic resonance spectroscopy (MRS) to directly measure whether kudzu extract alters the rate and concentration of alcohol that actually enters the human brain. Studies such as this will likely yield more information on how kudzu extract reduces alcohol consumption.

Some limitations of the present study should be noted. The sample size was relatively small; however, a repeated measures, crossover design was used with participants as their own control receiving multiple pretreatments, each with placebo and alcohol challenges. The present study did not include a treatment condition to specifically analyze the effects of kudzu alone in the absence of any challenge drink. Previous work in this laboratory on the stance stability test has indicated that kudzu alone does not alter this behavior (unpublished results). In the current study, the effects of kudzu pretreatment alone were analyzed through a comparison of results on the $1^{\text {st }}$ challenge day ('day 8'). This experimental day was always a placebo drink but after either a week of treatment with placebo or kudzu extract. Results from these experimental days again showed no effect of the kudzu extract alone on our measures.

In conclusion, a relatively short-term treatment with kudzu extract failed to have a significant effect on alcohol-induced intoxication and other psychomotor and cognitive effects. Thus, the mechanism of action of this herbal preparation to reduce alcohol consumption remains elusive.

\section{Acknowledgments}

This research was supported by NCCAM Grant AT00203 (SEL), NIAAA Grant AA10536 (SEL) and NIDA Grant DA000343 (SEL). McLean Hospital has negotiated a licensing agreement for the kudzu extract with Natural Pharmacia International, Inc., Burlington, MA 


\section{References}

Brasser SM, McCaul ME, Houtsmuller EJ. Alcohol effects during acamprosate treatment: a doseresponse study in humans. Alcohol Clin Exp Res. 2004; 28:1074-83. [PubMed: 15252294]

Conners, CK. Conners' Continuous Performance Test (CPT II) Users Manual. Multi-Health Systems, Inc., Multi-Health Systems, Inc.; 2000.

Del Boca FK, Kranzler HR, Brown J, Korner PF. Assessment of medication compliance in alcoholics through UV light detection of a riboflavin tracer. Alcohol Clin Exp Res. 1996; 20:1412-1417. [PubMed: 8947318]

Griffiths RR, Wurster RM, Brady JV. Choice between food and heroin: effects of morphine, naloxone, and secobarbital. J Exp Anal Behav. 1981; 35:335-51. [PubMed: 7241034]

Heyman GM, Keung WM, Vallee BL. Daidzin decreases ethanol consumption in rats. Alcohol Clin Exp Res. 1996; 20:1083-7. [PubMed: 8892531]

Holdstock L, King AC, de Wit H. Subjective and objective responses to ethanol in moderate/heavy and light social drinkers. Alcohol Clin Exp Res. 2000; 24:789-94. [PubMed: 10888066]

Jones AW, Lindberg L, Olsson S-G. Magnitude and time-course of arterio-venous differences in blood-alcohol concentration in healthy men. Clin Pharmacokinet. 2004; 43:1157-1166. [PubMed: 15568892]

Keung, WM. Preclinical studies of kudzu (Pueraria lobata) as as treatment for alcohol abuse. In: Keung, WM., editor. Pueraria: The genus Pueraria. Taylor \& Francis; New York: 2002. p. 144-158.

Keung WM, Klyosov AA, Vallee BL. Daidzin inhibits mitochondrial aldehyde dehydrogenase and suppresses ethanol intake of Syrian golden hamsters. Proc Natl Acad Sci U S A. 1997; 94:1675-9. [PubMed: 9050837]

Keung WM, Lazo O, Kunze L, Vallee BL. Daidzin suppresses ethanol consumption by Syrian golden hamsters without blocking acetaldehyde metabolism. Proc Natl Acad Sci U S A. 1995; 92:8990-3. [PubMed: 7568058]

Keung WM, Vallee BL. Daidzin and daidzein suppress free-choice ethanol intake by Syrian golden hamsters. Proc Natl Acad Sci U S A. 1993; 90:10008-12. [PubMed: 8234248]

Kim SW, Bae KY, Shin HY, Kim JM, Shin IS, Youn T, Kim J, Kim JK, Yoon JS. The Role of Acetaldehyde in Human Psychomotor Function: A Double-Blind Placebo-Controlled Crossover Study. Biol Psychiatry. 2009

Kouri EM, McCarthy EM, Faust AH, Lukas SE. Pretreatment with transdermal nicotine enhances some of ethanol's acute effects in men. Drug Alcohol Depend. 2004; 75:55-65. [PubMed: 15225889]

Li, SC. Ben Cho Gang Mu (1590-1596 A.D.). 1590-1596.

Lin RC, Guthrie S, Xie CY, Mai K, Lee DY, Lumeng L, Li TK. Isoflavonoid compounds extracted from Pueraria lobata suppress alcohol preference in a pharmacogenetic rat model of alcoholism. Alcohol Clin Exp Res. 1996; 20:659-63. [PubMed: 8800381]

Lukas SE, Lex BW, Slater JP, Greenwald NE, Mendelson JH. A microanalysis of ethanol-induced disruption of body sway and psychomotor performance in women. Psychopharmacology (Berl). 1989; 98:169-75. [PubMed: 2502789]

Lukas SE, Mendelson JH, Benedikt RA. Instrumental analysis of ethanol-induced intoxication in human males. Psychopharmacology (Berl). 1986; 89:8-13. [PubMed: 3090597]

Lukas SE, Penetar D, Berko J, Vicens L, Palmer C, Mallya G, Macklin EA, Lee DY. An extract of the Chinese herbal root kudzu reduces alcohol drinking by heavy drinkers in a naturalistic setting. Alcohol Clin Exp Res. 2005; 29:756-62. [PubMed: 15897719]

Melis M, Diana M, Enrico P, Marinelli M, Brodie MS. Ethanol and acetaldehyde action on central dopamine systems: mechanisms, modulation, and relationship to stress. Alcohol. 2009; 43:531-9. [PubMed: 19913196]

Overstreet DH, Lee Y-W, Chen YT, Rezvani AH. The Chinese herbal medicine NPI-028 suppresses alcohol intake in alcohol-preferring rats and monkeys without inducing taste aversion. J Perfusion. 1998; 11:381-389. 
Overstreet DH, Lee YW, Rezvani AH, Pei YH, Criswell HE, Janowsky DS. Suppression of alcohol intake after administration of the Chinese herbal medicine, NPI-028, and its derivatives. Alcohol Clin Exp Res. 1996; 20:221-7. [PubMed: 8730211]

Penetar DM, Kouri EM, McCarthy EM, Lilly MM, Peters EN, Juliano TM, Lukas SE. Nicotine pretreatment increases dysphoric effects of alcohol in luteal-phase female volunteers. Int J Environ Res Public Health. 2009; 6:526-46. [PubMed: 19440397]

Penetar DM, McNeil JF, Ryan ET, Lukas SE. Comparison among plasma, serum, and whole blood ethanol concentrations: impact of storage conditions and collection tubes. J Anal Toxicol. 2008; 32:505-10. [PubMed: 18713519]

Penetar DM, Teter CJ, Ma Z, Tracy M, Lee DY-W, Lukas SE. Pharmacokinetic profile of the isoflavone puerarin after acute and repeated administration of a novel kudzu extract to human volunteers. J Altern Complement Med. 2006; 12:543-548. [PubMed: 16884345]

Rooke N, Li DJ, Li J, Keung WM. The mitochondrial monoamine oxidase-aldehyde dehydrogenase pathway: a potential site of action of daidzin. J Med Chem. 2000; 43:4169-79. [PubMed: 11063613]

Sanchez-Catalan MJ, Hipolito L, Zornoza T, Polache A, Granero L. Motor stimulant effects of ethanol and acetaldehyde injected into the posterior ventral tegmental area of rats: role of opioid receptors. Psychopharmacology (Berl). 2009; 204:641-53. [PubMed: 19238363]

Sun, SM. Beiji-Quianjin-Yaofang. circa 600 AD

Tam WY, Chook P, Qiao M, Chan LT, Chan TY, Poon YK, Fung KP, Leung PC, Woo KS. The efficacy and tolerability of adjunctive alternative herbal medicine (Salvia miltiorrhiza and Pueraria lobata) on vascular function and structure in coronary patients. J Altern Complement Med. 2009; 15:415-21. [PubMed: 19388864]

Wurster RM, Griffiths RR, Findley JD, Brady JV. Reduction of heroin self-administration in baboons by manipulation of behavioral and pharmacological conditions. Pharmacol Biochem Behav. 1977; 7:519-28. [PubMed: 413116]

Yan LP, Zhuang YL, Chan SW, Chen SL, Shi GG. Analysis of the mechanisms underlying the endothelium-dependent antivasoconstriction of puerarin in rat aorta. Naunyn Schmiedebergs Arch Pharmacol. 2009; 379:587-97. [PubMed: 19190894]

Yeung DK, Leung SW, Xu YC, Vanhoutte PM, Man RY. Puerarin, an isoflavonoid derived from Radix puerariae, potentiates endothelium-independent relaxation via the cyclic AMP pathway in porcine coronary artery. Eur J Pharmacol. 2006; 552:105-11. [PubMed: 17027964]

Yue HW, Hu XQ. Medical evaluation of kudzu and puerarin on cardiovascular system. Chinese J Integr Tradit West Med. 1996; 16:382-384.

Zhang S, Chen S, Shen Y, Yang D, Liu X, Sun-Chi AC, Xu H. Puerarin induces angiogenesis in myocardium of rat with myocardial infarction. Biol Pharm Bull. 2006; 29:945-50. [PubMed: $16651724]$ 

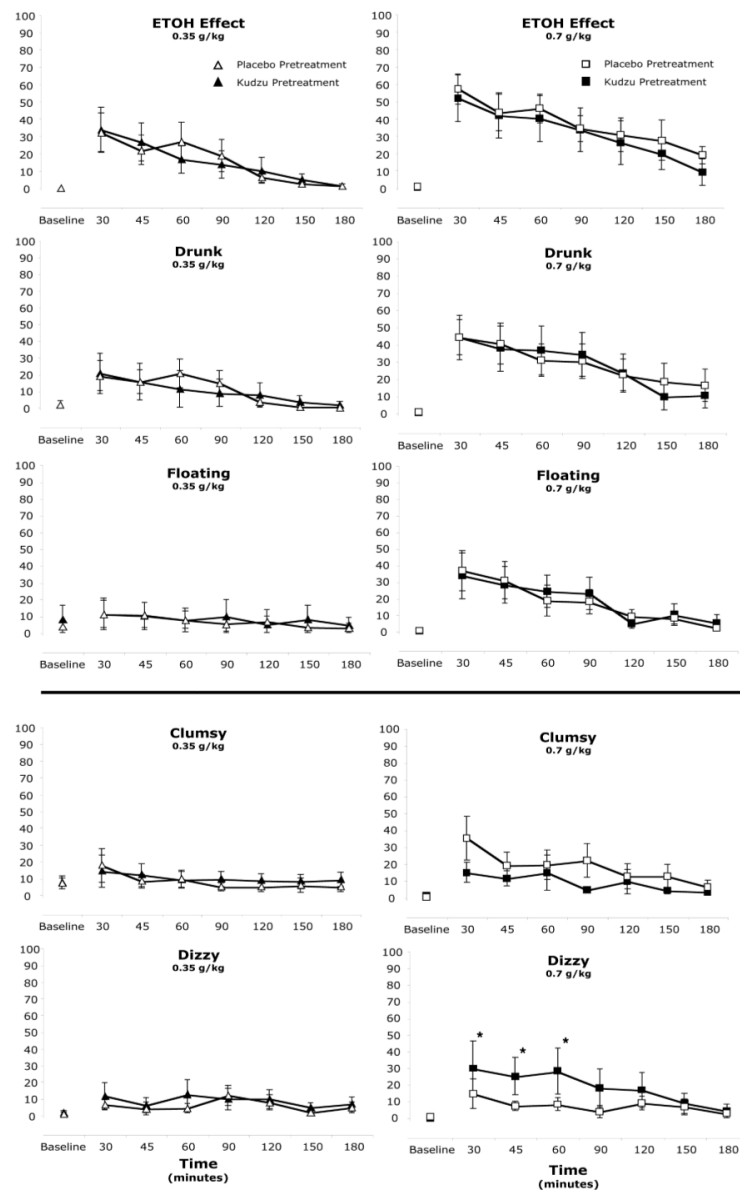

Figure 1.

Dose, time course, and pretreatment effects on 5 visual analog scales. Three 'positive' alcohol effect scales are shown in the top portion, and 2 'negative' alcohol effect scales are shown in the bottom portion. For clarity, ratings after the placebo drink challenge are not plotted (which generally ranged between 0 and 10 for the duration of the assessment period). * Scores following the kudzu pretreatment are significantly greater than scores following placebo pretreatment, $\mathrm{p}<.05$. See Table 1 for dose differences. 


\section{Alcohol Effects on Stance Stability}

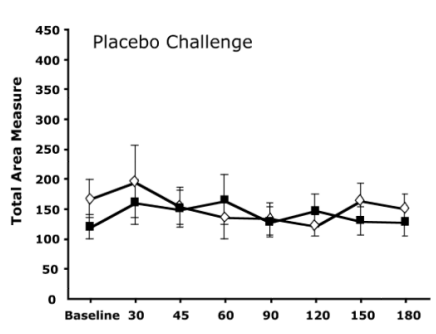

Stance: Eyes closed, Arms by side
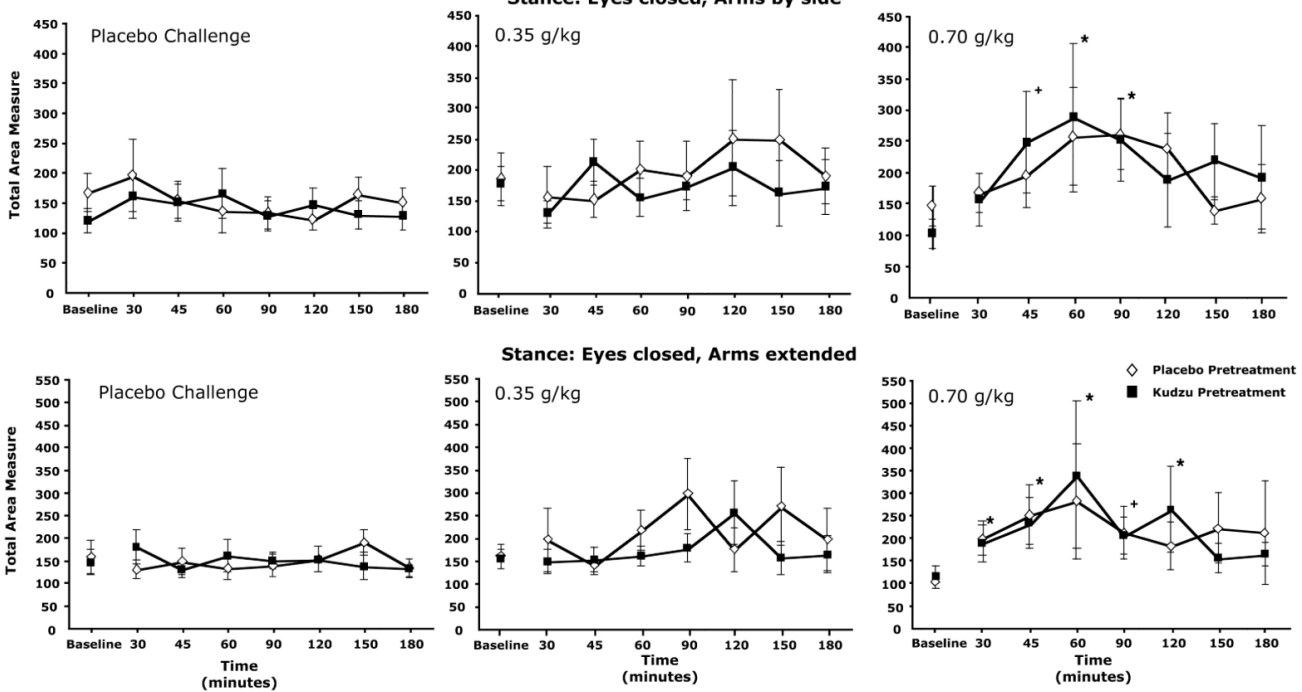

Figure 2.

Time course responses for total area measure of stance stability for two of the stances tested. Each panel shows responses following both placebo and kudzu pretreatment. Separate panels for each challenge dose tests are shown. * Measure significantly different from baseline (before alcohol drink administered), $\mathrm{p}<.05 .{ }^{+} \mathrm{p}=.058$ for arms by side; $\mathrm{p}=.051$ for arms extended. 


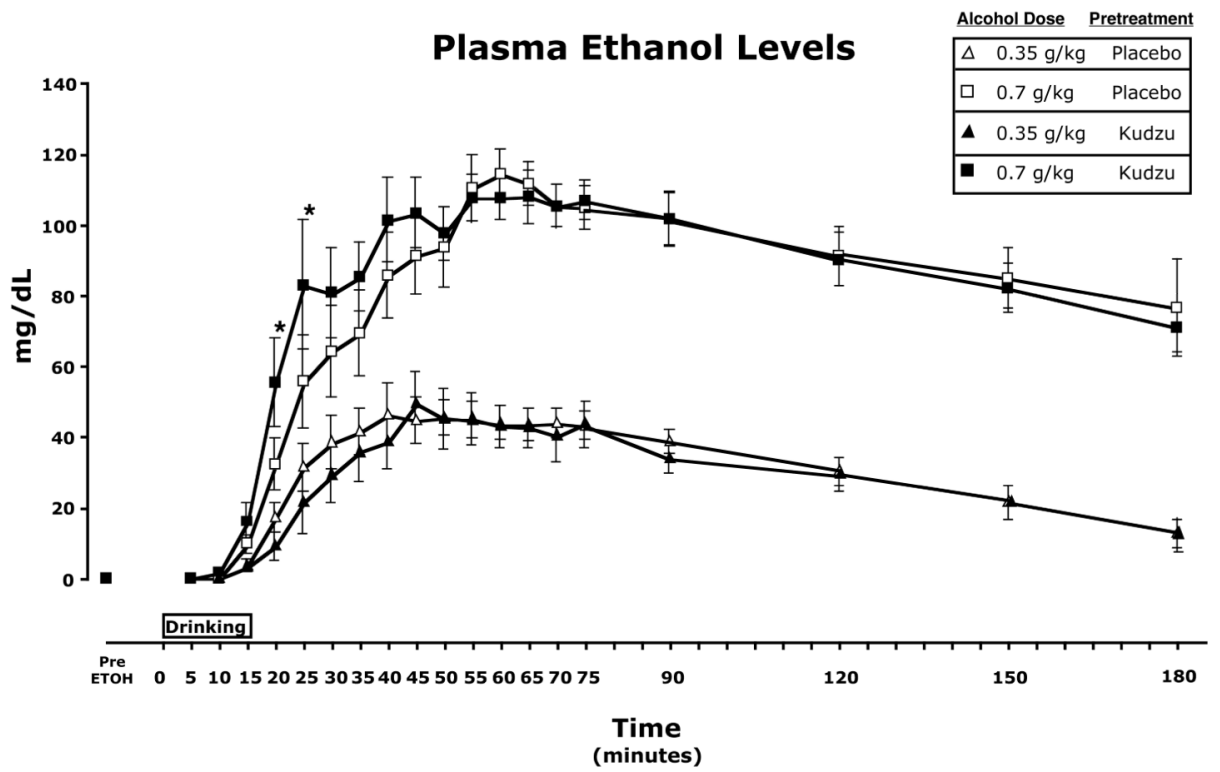

Figure 3.

Time course of plasma ethanol levels for each dose tested following placebo and kudzu pretreatment condition. * Ethanol levels for the $0.7 \mathrm{~g} / \mathrm{kg}$ dose significantly higher following kudzu pretreatment vs. placebo pretreatment. 


\section{Table 1}

Subjective Behavioral Measures of Intoxication: analysis of variance and post hoc testing results. Participants rated their response to the alcohol challenge $(0.35$ or $0.7 \mathrm{~g} / \mathrm{kg})$ on the following visual analog scales (VAS). Questions were posed to the participants in the form of "How do you feel right now?" or "How much do you (have) right now?" and rated on a scale from 0 - 'not at all' to 100 - 'extremely'

\begin{tabular}{|l|l|l|}
\hline VAS & ANOVA results & post hoc results \\
\hline Feel alcohol effects & $\mathrm{F}_{(2,336)}=110.626, p<.001$ & All dose conditions different \\
\hline Clumsy & $\mathrm{F}_{(2,336)}=5.241, p=.006$ & High dose greater than placebo \\
\hline Dizzy & $\mathrm{F}_{(2,336)}=19.2, p<.001$ & All dose conditions different \\
\hline Drunk & $\mathrm{F}_{(2,336)}=81.904, p<.001$ & All dose conditions different \\
\hline Floating & $\mathrm{F}_{(2,336)}=27.503, p<.001$ & High dose greater than low dose and placebo \\
\hline Great & $\mathrm{F}_{(2,336)}=9.256, p<.001$ & High dose and placebo greater than low dose \\
\hline High & $\mathrm{F}_{(2,336)}=22.177, p<.001$ & All dose conditions different \\
\hline Muddle/Confused & $\mathrm{F}_{(2,326)}=7.972, p<.001$ & High dose greater than low dose and placebo \\
\hline Nauseated & $\mathrm{F}_{(2,336)}=5.007, p=.007$ & Low dose greater than placebo \\
\hline Sleepy & $\mathrm{F}_{(2,336)}=3.042, p=.049$ & Low dose greater than high dose and placebo \\
\hline Slurred speech & $\mathrm{F}_{(2,336)}=38.9, p<.001$ & High dose greater than low dose and placebo \\
\hline Terrible & $\mathrm{F}_{(2,336)}=6.56, p=.002$ & Low dose greater than high dose and placebo \\
\hline Uncomfortable & $\mathrm{F}_{(2,336)}=8.529, p<.001$ & Low dose and placebo greater than high dose \\
\hline
\end{tabular}


Table 2

Pharmacokinetic Parameters (Means \pm standard error)

\begin{tabular}{|c|c|c|c|}
\hline & Dose & Placebo Pretreatment & Kudzu Pretreatment \\
\hline \multirow[t]{2}{*}{ Cmax (mg/dL) } & $0.35 \mathrm{~g} / \mathrm{kg}$ & $54.42 \pm 6.8$ & $50.67 \pm 7.4$ \\
\hline & $0.7 \mathrm{~g} / \mathrm{kg}$ & $119.45 \pm 6.8^{*}$ & $121.71 \pm 6.8^{*}$ \\
\hline \multirow[t]{2}{*}{ Tmax (minutes) } & $0.35 \mathrm{~g} / \mathrm{kg}$ & $53.33 \pm 7.1$ & $59.0 \pm 7.8$ \\
\hline & $0.7 \mathrm{~g} / \mathrm{kg}$ & $66.67 \pm 7.1$ & $55.83 \pm 7.1$ \\
\hline \multirow{2}{*}{$\begin{array}{l}\text { Absorption Rate }{ }^{l} \\
(\mathrm{mg} . \mathrm{dL} / \mathrm{min})\end{array}$} & $0.35 \mathrm{~g} / \mathrm{kg}$ & $1.137 \pm .34$ & $0.932 \pm .37$ \\
\hline & $0.7 \mathrm{~g} / \mathrm{kg}$ & $1.839 \pm .34^{*}$ & $2.653 \pm .34^{*}$ \\
\hline \multirow[t]{2}{*}{$\mathrm{AUC}_{0-180}(\mathrm{mg} \cdot \mathrm{hr} / \mathrm{dL})$} & $0.35 \mathrm{~g} / \mathrm{kg}$ & $82.6 \pm 21.2$ & $84.9 \pm 23.2$ \\
\hline & $0.7 \mathrm{~g} / \mathrm{kg}$ & $198.3 \pm 21.2^{*}$ & $228.8 \pm 21.2^{*}$ \\
\hline \multirow[t]{2}{*}{$\mathrm{AUC}_{0 \text {-inf }}(\mathrm{mg} \cdot \mathrm{hr} / \mathrm{dL})$} & $0.35 \mathrm{~g} / \mathrm{kg}$ & $130.2 \pm 44.7$ & $110.8 \pm 48.9$ \\
\hline & $0.7 \mathrm{~g} / \mathrm{kg}$ & $598.9 \pm 44.7^{*}$ & $533.3 \pm 44.7^{*}$ \\
\hline \multirow{2}{*}{$\begin{array}{l}\text { Elimination Rate } \\
(\mathrm{mg} . \mathrm{dL} / \mathrm{min})\end{array}$} & $0.35 \mathrm{~g} / \mathrm{kg}$ & $0.279 \pm .03$ & $0.297 \pm .04$ \\
\hline & $0.7 \mathrm{~g} / \mathrm{kg}$ & $0.315 \pm .036$ & $0.388 \pm .03$ \\
\hline
\end{tabular}

${ }^{1}$ Absorption Rate was calculated by dividing Cmax/Tmax (after Jones et al., 2004).

2 Elimination Rate is the slope of the elimination curve.

* $0.7 \mathrm{~g} / \mathrm{kg}$ dose significantly higher than the $0.35 \mathrm{~g} / \mathrm{kg}$ dose. There were no significant differences due to pretreatment. 